\title{
Investigation of CNC Turning Parameters by Using a Vortex Tube Cooling System
}

\author{
S. YÜKSEL ${ }^{a, *}, A \cdot$ ONAT $^{b}$ \\ ${ }^{a}$ Department of Mechanical R\&D, VİKO Elektrik ve Elektronik Endüstrisi San. ve Tic. A.Ş., 3488, Istanbul, Turkey \\ ${ }^{b}$ Marmara University, Technical Education Faculty, Energy Department, Istanbul, Turkey
}

\begin{abstract}
Controlling the heat, generated during the cutting process, is an important factor in improving the quality of the product and performance of the machining. A vortex tube was employed to evaluate the effects of cooling on the turning parameters. Various cutting parameters $(100 \mathrm{~m} / \mathrm{min}, 250 \mathrm{~m} / \mathrm{min}$ and $400 \mathrm{~m} / \mathrm{min})$ together with various cooling temperatures $\left(-4{ }^{\circ} \mathrm{C}, 8{ }^{\circ} \mathrm{C}\right.$ and $\left.20^{\circ} \mathrm{C}\right)$ were considered to find surface roughness, cutting force and cutting temperature. Response surface methodology was used to optimize the experimental parameters. The best attainable surface roughness value was found to be $0.77 \mu \mathrm{m}$ Ra, under the conditions of $0.15 \mathrm{~mm} / \mathrm{rev}$ feed, $400 \mathrm{~m} / \mathrm{min}$ cutting speed, $-4{ }^{\circ} \mathrm{C}$ (with vortex tube) cutting temperature and $1.2 \mathrm{~mm}$ tool edge radius. Cutting forces were not affected by the temperature changes. The difference was negligible and as small as $1 \%$. The minimum cutting temperature was $74.17^{\circ} \mathrm{C}$, which was obtained under the machining conditions of $0.25 \mathrm{~mm}$ feed, $250 \mathrm{~m} / \mathrm{min}$ cutting speed $-4{ }^{\circ} \mathrm{C}$ (with vortex tube) cutting temperature and $0.8 \mathrm{~mm}$ tool edge radius.
\end{abstract}

DOI: 10.12693/APhysPolA.127.881

PACS: $81.20 . \mathrm{Wk}$

\section{Introduction}

During the machining of a work piece, most of the energy is converted to heat due to the shear stresses. Therefore the heat which is generated in the cutting zone has a great importance in terms of performance and quality of the work piece in the machining process. Although, the use of the cutting liquids improves the cooling performance, it increases the cost of production and has really harmful effect on environment. Due to these reasons, the necessity for finding out different cooling techniques gradually increases. Especially the studies on sustainable manufacturing have increased in recent years. One of such cooling methods is the vortex tube cooling system. Vortex tube is a simple, compact, light and quiet device, which can separate an incoming compressed gas stream of uniform temperature into two streams, one warmer than the inlet stream and the other colder than the inlet stream. Such separation of the gaseous fluid stream into two different streams of higher and lower temperatures is referred to as temperature (energy) separation effect. Ranque invented the vortex tube and reported about the energy separation. Later Hilsch published systematic experimental results of this effect. Since then, this phenomenon has attracted many scientists. Various theories have been proposed to explain this phenomenon by experimental, analytical and numerical studies. Hilsch suggested that the expansion of air from high pressure near the wall to low pressure near the axis generates a velocity gradient in radial direction which results in transfer of kinetic energy by the viscous force from the inner fluid layers to the outer fluid layers $[1,2]$. A Ranque-Hilsch

* corresponding author; e-mail: semihyuksel@yandex.com
Vortex Tube (RHVT) consists of one or more inlet nozzles, a vortex chamber, a cold-end orifice, a hot-end control valve and a tube. Special internal configurations of the designed vortex chamber combine effects of pressure and accelerated air, leading to a high rate of rotation [3]. The vortex tube can be applied to many industrial applications such as cooling system of $\mathrm{CNC}$ machines, refrigerators, cooling suits, heating process, etc. Since, it has no moving parts, it does not break or wear and therefore it requires little maintenance [4]. A schematic view of vortex tube is shown in Fig. 1.

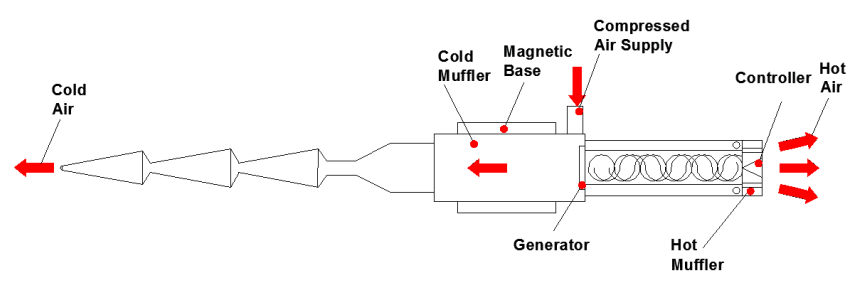

Fig. 1. Schematic view of vortex tube.

Chilled air, generated by a vortex tube (VT), has been investigated as an alternative cooling method for efficient heat dissipation in machining [5]. Aronson tested VTs in high-speed drilling and reported that VT cooling may improve the tool life by ten times [6]. Liu and Hou applied VT cooling in steel turning and claimed that VT cooling may reduce crater wear, flank wear, and the flank wearrate [7]. Choi et al. reported that VT cooling is capable of reducing surface roughness and generating compressive residual stresses at the workpiece surface in cylindrical grinding [2]. Nguyen and Zhang combined VT cooling and oil mist during surface grinding and demonstrated that a small amount of vegetable oil adds lubrication to cold-air cooling and improves the material removal rate under identical part quality constraints [8]. 
Parameters used in the CNC turning.

TABLE I

\begin{tabular}{c|c|c|c|c}
\hline \hline & $\begin{array}{c}\text { Cutting } \\
\text { Speed }(v) \\
{[\mathrm{m} / \mathrm{min}]}\end{array}$ & $\begin{array}{c}\text { Feed } \\
(f) \\
{[\mathrm{mm} / \mathrm{rev}]}\end{array}$ & $\begin{array}{c}\text { Tool } \\
\text { Edge }(r) \\
{[\mathrm{mm}]}\end{array}$ & $\begin{array}{c}\text { Cutting } \\
\text { Temp. }(T) \\
{\left[{ }^{\circ} \mathrm{C}\right]}\end{array}$ \\
\hline Min. & 100 & 0.15 & 0.4 & -4 \\
\hline Mean & 250 & 0.25 & 0.8 & 8 \\
\hline Max. & 400 & 0.35 & 1.2 & 20
\end{tabular}

\section{Materials and method}

2.1. Material

In this experiment three different cutting tools with varying radii were used for the $\mathrm{CNC}$ turning of low alloy chromium molybdenum steel (42CrMo4) specimen, having a diameter of $50 \mathrm{~mm}$ and a length of $120 \mathrm{~mm}$. The machining was performed under the conditions of constant depth of the cut $(2.5 \mathrm{~mm})$.

The relationship response obtained through input parameters.
The other machining parameters (feed, cutting speed, cutting temperature and tool geometry) are shown in Table I. A schematic detail of experimental set-up is given in Fig. 2.

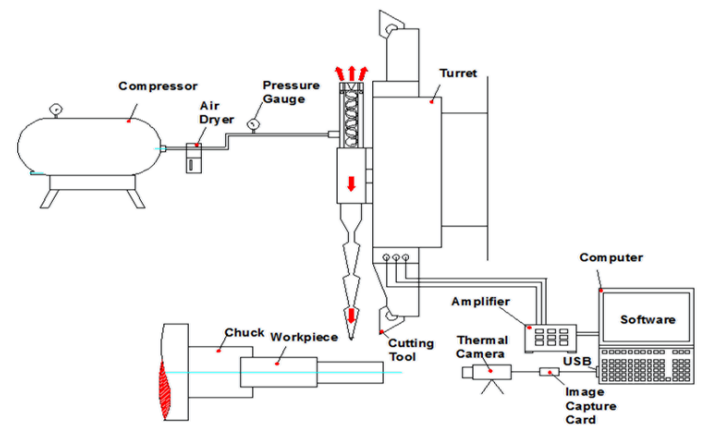

Fig. 2. A schematic detail of experimental set-up.

TABLE II

\begin{tabular}{|c|c|c|c|c|c|c|c|c|c|}
\hline $\begin{array}{c}\text { Run } \\
\text { Order }\end{array}$ & $\begin{array}{c}\mathrm{Pt} \\
\text { Type }\end{array}$ & Blocks & $\begin{array}{c}\text { Feed } \\
{[\mathrm{mm} / \mathrm{rev}]}\end{array}$ & $\begin{array}{c}\text { Cutting Speed } \\
{[\mathrm{m} / \mathrm{min}]}\end{array}$ & $\begin{array}{c}\text { Cutting Temp. } \\
{\left[{ }^{\circ} \mathrm{C}\right]}\end{array}$ & $\begin{array}{c}\text { Tool Edge } \\
r[\mathrm{~mm}]\end{array}$ & $\begin{array}{c}\text { Roughness } \\
(R a)\end{array}$ & $\begin{array}{c}\text { Cutting } \\
\text { Force }[\mathrm{N}]\end{array}$ & $\begin{array}{c}\text { Temperature } \\
{\left[{ }^{\circ} \mathrm{C}\right]}\end{array}$ \\
\hline 1 & 1 & 1 & 0.35 & 100 & 20 & 1.2 & 3.88 & 943.90 & 234.1 \\
\hline 2 & -1 & 1 & 0.15 & 250 & 8 & 0.8 & 1.38 & 530.23 & 132.4 \\
\hline 3 & -1 & 1 & 0.25 & 250 & 20 & 0.8 & 2.73 & 689.93 & 224.0 \\
\hline 4 & 0 & 1 & 0.25 & 250 & 8 & 0.8 & 2.11 & 697.26 & 86.20 \\
\hline 5 & 1 & 1 & 0.15 & 400 & 20 & 1.2 & 1.08 & 523.05 & 281.9 \\
\hline 6 & 1 & 1 & 0.15 & 100 & -4 & 0.4 & 1.76 & 483.78 & 152.1 \\
\hline 7 & 0 & 1 & 0.25 & 250 & 8 & 0.8 & 2.33 & 722.09 & 74.10 \\
\hline 8 & 1 & 1 & 0.15 & 400 & -4 & 1.2 & 0.77 & 473.12 & 187.0 \\
\hline 9 & -1 & 1 & 0.25 & 400 & 8 & 0.8 & 2.33 & 699.88 & 164.1 \\
\hline 10 & 0 & 1 & 0.25 & 250 & 8 & 0.8 & 2.33 & 722.09 & 74.10 \\
\hline 11 & -1 & 1 & 0.35 & 250 & 8 & 0.8 & 3.70 & 922.49 & 164.0 \\
\hline 12 & 0 & 1 & 0.25 & 250 & 8 & 0.8 & 2.33 & 722.09 & 74.10 \\
\hline 13 & -1 & 1 & 0.25 & 250 & -4 & 0.8 & 1.99 & 717.23 & 56.30 \\
\hline 14 & 1 & 1 & 0.35 & 100 & -4 & 1.2 & 3.23 & 933.78 & 114.3 \\
\hline 15 & 0 & 1 & 0.25 & 250 & 8 & 0.8 & 2.09 & 702.06 & 109.8 \\
\hline 16 & 1 & 1 & 0.35 & 400 & -4 & 0.4 & 5.30 & 878.16 & 129.6 \\
\hline 17 & -1 & 1 & 0.25 & 250 & 8 & 0.4 & 3.55 & 640.37 & 117.7 \\
\hline 18 & -1 & 1 & 0.25 & 250 & 8 & 1.2 & 1.85 & 696.11 & 184.3 \\
\hline 19 & 0 & 1 & 0.25 & 250 & 8 & 0.8 & 2.26 & 697.03 & 99.60 \\
\hline 20 & 1 & 1 & 0.35 & 100 & -4 & 0.4 & 4.82 & 932.37 & 123.9 \\
\hline 21 & 1 & 1 & 0.15 & 100 & -4 & 1.2 & 1.43 & 522.27 & 144.7 \\
\hline 22 & 1 & 1 & 0.35 & 400 & 20 & 1.2 & 3.77 & 914.54 & 253.3 \\
\hline 23 & 1 & 1 & 0.15 & 400 & 20 & 0.4 & 2.03 & 444.04 & 168.4 \\
\hline 24 & 1 & 1 & 0.15 & 100 & 20 & 0.4 & 2.18 & 477.11 & 234.2 \\
\hline 25 & -1 & 1 & 0.25 & 100 & 8 & 0.8 & 2.42 & 746.34 & 129.7 \\
\hline 26 & 1 & 1 & 0.35 & 400 & 20 & 0.4 & 6.63 & 874.16 & 165.5 \\
\hline 27 & 1 & 1 & 0.15 & 100 & 20 & 1.2 & 1.71 & 475.05 & 292.5 \\
\hline 28 & 0 & 1 & 0.25 & 250 & 8 & 0.8 & 2.06 & 704.28 & 112.3 \\
\hline 29 & 1 & 1 & 0.35 & 400 & -4 & 1.2 & 2.82 & 903.38 & 168.2 \\
\hline 30 & 1 & 1 & 0.15 & 400 & -4 & 0.4 & 1.62 & 445.23 & 131.8 \\
\hline 31 & 1 & 1 & 0.35 & 100 & 20 & 0.4 & 5.95 & 936.11 & 190.7 \\
\hline
\end{tabular}




\subsection{Method}

The data were optimized by means of response surface methodology in Minitab program. The graphics were created by using the acquired data. The temperature attained through the use of vortex tube and surface quality were examined. The tool temperature was measured via FLIR E7 thermal camera during the cutting process. The measurements performed in this way were computerized and saved as cutting force data. Surface roughness measurements were conducted on the work piece. The mean value of three measurements was used in the analysis. Then the response surface method was employed by Minitab program using Eq. 1.

$$
Y_{u}=b_{0}+\sum_{i=1}^{k} b_{i} X_{i u}+\sum_{i=1}^{k} b_{i i} X_{i u}^{2}+\sum_{i=1}^{k} b_{i j} X_{i u} X_{j u}
$$

Where, $Y_{u}$ represent surface roughness, cutting force and temperature, $X_{i u}$ are coded values of the machining parameters, $k$ is number of machining parameters and $b_{0}$, $b_{i}, b_{i i}, b_{i j}$ are regression coefficients of the model to be determined.

Design of the experiment (DOE) features of MINITAB software is utilized to determine the coefficients of the mathematical modeling, based on the response surface regression model. The values of the regression coefficients of linear, quadratic and interaction terms of the model are determined using Eq. 2.

$$
b=\left(X^{T} X\right)^{-1} X^{T} Y
$$

Where, $b$ are regression Coefficients, $X$ is calculation matrix which contains the coded values of main and interaction terms, $X^{T}$ transpose of $\mathrm{X},\left(X^{T} X\right)^{-1}$ inverse matrix of $\left(X^{T} X\right)$ and $Y$ is matrix of measured/simulated response.

The mathematical relationship between the surface roughness $(R a)$ and the considered machining process parameters can be expressed as follows,

$$
\begin{aligned}
Y_{u} & =0.874813+10.7753(f)+0.000628077(v) \\
& +0.0206737(t)-2.45910(r)+21.3162(f)^{2} \\
& +1.90052 \times 10^{-6}(v)^{2}-0.00150374(t)^{2}+2.28664(r)^{2} \\
& -0.00233350(f v)+0.0143771(f t)-9.70319(f r) \\
& -7.42917 \times 10^{-6}(v t)-0.00193912(v r)-0.00605260(t r) .
\end{aligned}
$$

The mathematical relationship between the cutting force $(F)$ and the considered machining process parameters can be expressed as follows,

$$
\begin{aligned}
Y_{u} & =152.631+1421.68(f)-0.465556(v) \\
& -1.04750(t)+428.085(r)+1815.60(f)^{2} \\
& +0.000662619(v)^{2}-0.0320778(t)^{2}-249.780(r)^{2} \\
& -0.429766(f v)+1.36247(f t)-107.132(f r) \\
& +0.00333092(v t)+0.132160(v r)+0.418107(t r) .
\end{aligned}
$$

The mathematical relationship between the temperature $(T)$ and the considered machining process parameters can be expressed as follows,

$$
\begin{aligned}
& Y_{u}=338.619-947.082(f)-0.408749(v) \\
& \quad+3.12186(t)-226.478(r)+2172.07(f)^{2} \\
& \quad+0.000907585(v)^{2}-0.180412(t)^{2}+153.254(r)^{2} \\
& \quad-0.526250(f v)-4.35938(f t)-112.656(f r) \\
& \quad-0.00323958(v t)+0.188646(v r)+2.69922(t r) .
\end{aligned}
$$

The "Face center" method was used for the design of experiment (DOE) and afterwards the experiments were carried out. Experimental results are listed in Table II. The experimental data was converted to Minitab Software format and optimized via the "Response surface" method. Then, the full factorial results of experiments were predicted using optimization results, and the results were used for construction of surface parameter graphics.

\section{Results and discussions}

\subsection{Surface roughness}

The differences between the optimized and measured values were found to be as small as $1 \%$. The best attainable surface roughness value was $0.77 \mu \mathrm{m}$ Ra. This roughness value was ensured under the conditions of $0.15 \mathrm{~mm} / \mathrm{rev}$ feed, $400 \mathrm{~m} / \mathrm{min}$ cutting speed, $-4{ }^{\circ} \mathrm{C}$ (with vortex tube) cutting temperature, $1.2 \mathrm{~mm}$ tool edge ra-
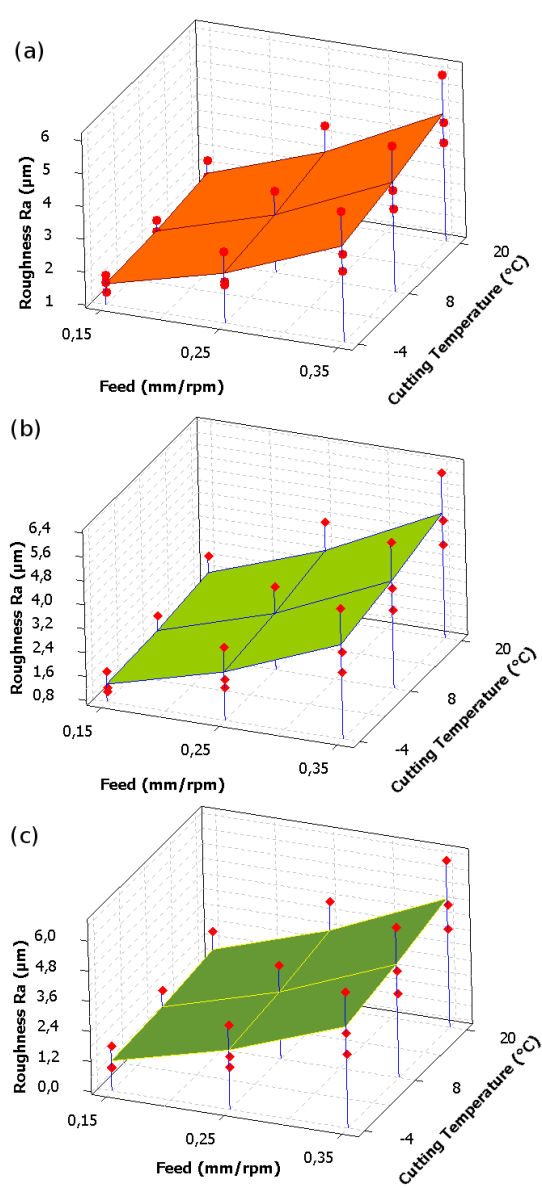

Fig. 3. Surface roughness (a) $V=100 \mathrm{~m} / \mathrm{min}$, (b) $V=$ $250 \mathrm{~m} / \mathrm{min}$, (c) $V=400 \mathrm{~m} / \mathrm{min}$. 
dius. The worst attainable surface roughness value was $6.52 \mu \mathrm{m}$ Ra. This roughness value was obtained under the conditions of $0.35 \mathrm{~mm} / \mathrm{rev}$ feed, $400 \mathrm{~m} / \mathrm{min}$ cutting feed, $20{ }^{\circ} \mathrm{C}$ (dry air) cutting temperature and $0.4 \mathrm{~mm}$ tool edge radius. Surface roughness graphs obtained under three different cutting speeds are presented in Fig. 3.

\subsection{Cutting forces}

The cutting force data was statistically calculated in Minitab by response surface methodology. The deviation between measured and optimized data was found to be around $4 \%$. It was deduced that difference in cutting force results in a difference of temperature. However the difference was negligible and as small as $1 \%$. It was concluded that the cutting force is not directly related to temperature. Cutting force graphs obtained under three different cutting speeds are presented in Fig. 4.
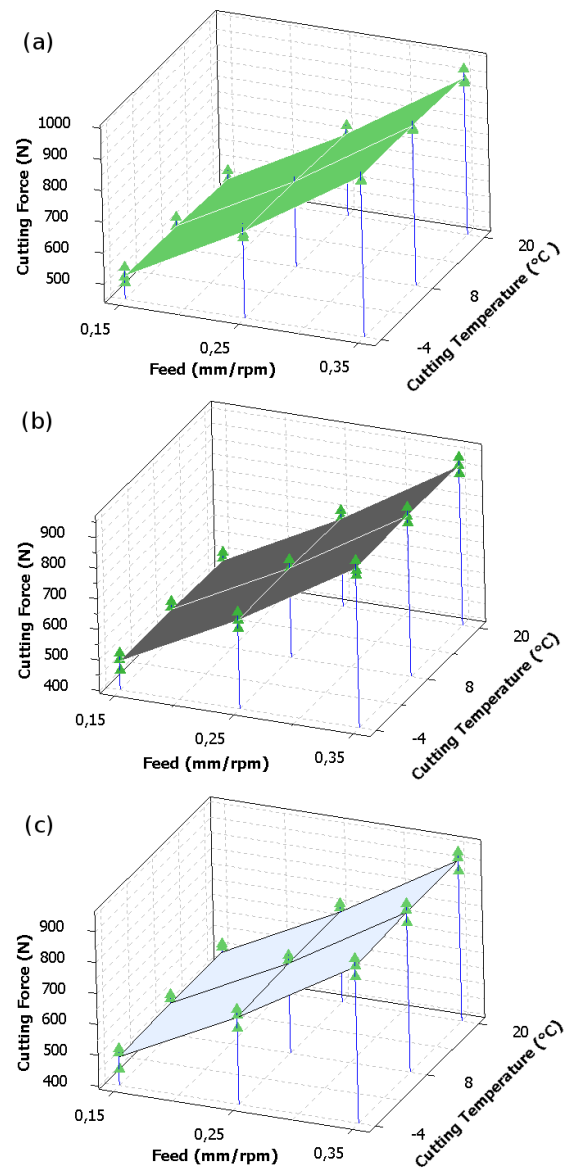

Fig. 4. Cutting forces (a) $V=100 \mathrm{~m} / \min$ (b) $V=$ $250 \mathrm{~m} / \mathrm{min}(\mathrm{c}) V=400 \mathrm{~m} / \mathrm{min}$.

\subsection{Temperature generated between the cutting tool and work piece}

The temperature data was statistically calculated in Minitab Program by response surface methodology. The deviation between measured and optimized data was found to be around $3 \%$. The minimum temperature was $74.17^{\circ} \mathrm{C}$. This temperature was obtained under the machining conditions of $0.25 \mathrm{~mm}$ feed, $250 \mathrm{~m} / \mathrm{min}$ cutting speed, $-4{ }^{\circ} \mathrm{C}$ (with vortex tube) cutting temperature and $0.8 \mathrm{~mm}$ tool edge radius. The highest temperature was found to be $292.79{ }^{\circ} \mathrm{C}$. It was obtained under the machining conditions of $0.15 \mathrm{~mm} /$ feed, $100 \mathrm{~m} / \mathrm{min}$ cutting speed, $20{ }^{\circ} \mathrm{C}$ (without vortex) cutting temperature and $1.2 \mathrm{~mm}$ tool edge radius. Temperature graphs obtained under three different cutting speeds are presented in Fig. 5.
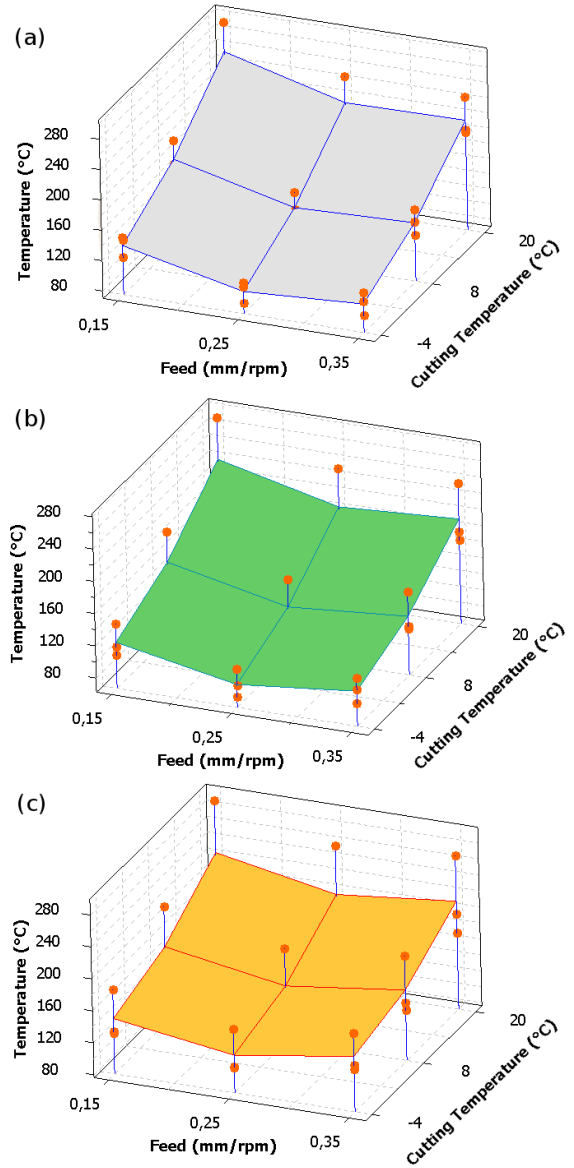

Fig. 5. The temperature formed between the cutting tool and work piece (a) $V=100 \mathrm{~m} / \mathrm{min}$, (b) $V=$ $250 \mathrm{~m} / \mathrm{min}(\mathrm{c}) V=400 \mathrm{~m} / \mathrm{min}$.

\section{Conclusions}

The general conclusions drawn from the study are summarized below:

- When the same machining parameters were used, the maximal improvement in surface roughness was found to be $37 \%$ in the case of vortex tube utilization at $-4^{\circ} \mathrm{C}$ compared to machining at $20^{\circ} \mathrm{C}$.

- When the same machining parameters were used, the difference in cutting force as small as $1 \%$ was observed. It was concluded that temperature changes obtained through the use of vortex tube have a very slight effect on the cutting force.

- When the same machining parameters were used, the temperature generated between the cutting tool 
and the work piece was reduced by $125 \%$ in the case of vortex tube utilization at $-4^{\circ} \mathrm{C}$, compared to machining at $20^{\circ} \mathrm{C}$. When feed rate increases, feed force also increases under the conditions of constant cutting speed.

- When feed rate increases, the temperature of the cutting tool also increases under the conditions of constant cutting speed. The temperature changes in accordance with the used tool's edge type.

- When the tool's edge radius was reduced, the surface roughness has increased under the conditions of constant cutting speed.

\section{Acknowledgments}

Financial support of this study by the research fund of the Marmara University under Grant No BAPKO FENC-YLP-130612-0228 is gratefully acknowledged.

\section{References}

[1] T. Dutta, K.P. Sinhamahapatra, S.S. Bandyopdhyay, International Journal of Refrigeration 33, 783 (2010).

[2] H.Z. Choi, S.W.Lee, H.D. Jeong, Journal of Materials Processing Technology 111, 265 (2001).

[3] A.M. Pinar, O. Uluer, V. Kirmaci, International Journal of Refrigeration 32, 1487 (2009).

[4] V. Kırmac1, International Journal of Refrigeration 32, 1626 (2009).

[5] T.T. Cockerill, Thermodynamics \& fluid mechanics of a ranquehilsch vortex tube, Thesis, University of Cambridge, 1998

[6] R.B. Aronson, Machine Design 48, 140 (1976).

[7] C. Liu, R. Hu, Manufacturing Technology \& Machine Tool 1, 30 (1997).

[8] T. Nyugan, L.C. Zhang, Journal of Materials Processing Technology 140, 224 (2003). 